\section{Sensorial Ability, Mastication and Nutrition of Single- Implant Overdentures Wearers}

\author{
Camilla Fraga do Amaral ${ }^{1}$, Gustavo Almeida Souza ${ }^{2}$, Mayara Abreu \\ Pinheiro ${ }^{1}$, Camila Heitor Campos $^{3}$, Renata Cunha Matheus Rodrigues Garcia ${ }^{1}$
}

\author{
'Department of Prosthodontics \\ and Periodontology, Piracicaba \\ Dental School, UNICAMP \\ - Universidade Estadual de \\ Campinas, Piracicaba, SP, Brazil \\ ${ }^{2}$ Department of Oral and Maxillofacial \\ Surgery, Piracicaba Dental School, \\ UNICAMP - Universidade Estadual \\ de Campinas, Piracicaba, SP, Brazil \\ ${ }^{3}$ Department of Specific Formation, \\ Nova Friburgo Health Institute, UFF \\ - Universidade Federal Fluminense, \\ Nova Friburgo, RJ, Brazil
}

Correspondence: Renata Cunha Matheus Rodrigues Garcia, Avenida Limeira, $n^{\circ}$ 901, Bairro Areião, 13414-903 Piracicaba, SP, Brasil. Tel.: +55-19-2106-5240. e-mail: regarcia@fop.unicamp.br

\author{
Key Words: edentulous \\ treatment, food comminution, \\ somatosensory system
}

\section{Introduction}

Complete denture (CD) wearers with severely loss of bone height may present chewing problems due to the lack of retention and stability of the mandibular dentures (1), which could negatively impact food selection and nutritional intake among elderly individuals, reflecting in their frailty process (2). The performance of masticatory processes, such as positioning of food between the teeth, breaking down it into smaller particles, and preparing bolus food for swallowing, is considered to be essential for proper oral function (3).

In the body, the somatosensory system is responsible for the oral tactile perception of stimuli, whether mechanical, chemical or physical. Sensory innervation involves receptors in periodontal ligament, oral mucosa, muscles of mastication, and the temporomandibular joints (4). Neurophysiological interactions at the cerebral cortex between sensory and motor units of the trigeminal nerve are necessary in order to chewing muscles prosecute function (5). In the absence of teeth, spatial control of jaw movements during mastication is impaired and masticatory forces are reduced in elders (3). Oral motor ability may also be impaired because of the absence of proprioception from the periodontal ligament and the denture's coverage of some receptors (1).

To improve the masticatory function and food comminution of elders with loss of residual ridges height, overdentures with two mandibular implants have been used (6). The use of a mandibular single-implant overdenture (SIO) opposing a maxillary CD have also been proposed for such patients, due to advantages such as less-invasive implant surgery and reduced component costs (7). Although $\mathrm{SIO}$ use has been reported to improve patients' masticatory efficiency, satisfaction, and quality of life $(8,9)$, little is known about whether it can improve nutrient intake among elderly people.

Usually, CD wearers present lower intake of fruits, vegetables and fibers (10). Conversely, they consume more foods containing saturated fat in comparison with similar dentate individuals (11). In addition, elders may adjust their diet composition by refusing raw foods or cooking it for more time in order to make it easier to prosecute chewing function, which reduce their nutritional daily intake (10). However, according to some authors (12), two implantsupported mandibular overdentures insertion improves nutritional state of edentulous elderly people (12), because its better retention and stability (13). Thus, considering that SIO also improves prosthesis stability (7), it can be 
supposed that it should also influence nutritional intake of elderly people.

Besides the prosthetic factor, masticatory performance (MP), can be associated with oral sensorimotor ability (OSA). Oral sensory receptors located at the oral mucous membrane perceive physical foods, initiate coordination of oral motor muscle functions to chew and prepare food bolus for swallowing (14). Thus, one could reasonably suppose that the age-related decline in oral sensory function (1) impairs mastication, ultimately contributing to poor nutrient intake, in edentulous elders. OSA is known to be similar in patients with two-implant overdentures and those with implant-supported fixed prostheses (15). However, no report has described OSA in edentulous elders who have undergone rehabilitation with SIO.

In addition, mastication is controlled by peripheral and central nervous feedback system, and the sensory awareness when chewing provides information about the relative position and movements of the mandible (15). Therefore, OSA could also influence masticatory movements of edentulous elderly patients using SIO.

Considering that an SIO can improve function by providing stability and retention to the mandibular prosthesis (8), the study hypothesis is that SIO could also improve the sensory function and mastication of elderly people with loss of residual ridges. Thus, the aim of the present study was to determine whether the increased mandibular retention and stability provided by an SIO improves OSA, chewing movements, MP, and nutritional intake of edentulous elderly patients.

\section{Material and Methods}

This unblinded observational clinical trial had a paired and controlled design. The Ethics Committee of Piracicaba Dental School, University of Campinas (Piracicaba, Brazil), approved the research protocol (\#087/2015). Participants signed an informed consent document after being given a full explanation of the study.

Completely edentulous subjects first received new conventional CDs. Later, single implants were installed in the anterior region of the mandible by a single operator. Then, conventional CDs were converted to SIOs by a distinct researchers after a healing period. After 2 months use of each prosthetic treatment, OSA, mandibular movements, $M P$, and nutritional intake were evaluated. To reduce bias, the researcher responsible for the prosthetics procedures did not collect data.

Subjects had participated in a previous study (16) and were recruited from patients seeking surgical or prosthetic treatment at Piracicaba Dental School, University of Campinas. The inclusion criteria were patient age of 60 years or older; good general health or adequately medication-controlled systemic disease, such as hypertension or diabetes; normal salivary flow rates $(>0.70 \mathrm{~g} / \mathrm{mL}$ ); completely edentulous, classified as Type III or IV according to the American College of Prosthodontics classification (17); and current use of unsatisfactory $C D$, according to the Rise Index (18). Completely edentulous subjects classified as Type IV must present enough bone in the mandibular midline region for an implant length of $11 \mathrm{~mm}$, evaluated by panoramic radiography. Volunteers presenting signs and symptoms of temporomandibular disorders, evaluated by palpation of masticatory muscle and by asking subjects about the presence of pain in the orofacial region were excluded. In addition, elders with uncontrolled systemic diseases, neurodegenerative diseases, osteoporosis, smokers and alcoholics were also excluded.

The sample size was estimated taking into account the variable of masticatory performance, which represents greater variability in the study. The calculation was performed using SAS software (release 9.1, 2003; SAS Institute Inc., Cary, NC, USA) and was based on a previous study (6). It indicated that the inclusion of 12 volunteers would be sufficient to detect significant differences (80\% power, 5\% error probability).

During the first clinical examination, all patients had their CD evaluated by two calibrated researchers $(I C C=1)$ using the Rise Index (18), and the residual bone height was verified. To measure the salivary flow rate, subjects were asked to chew a piece of tasteless parafilm (Parafilm $\mathrm{M}^{\oplus}$; Bemis Company, Inc., Neenah, WI, USA) for 5 min, and to expectorate the saliva produced into a pre-weighed cup at 30 -s intervals. The salivary flow rate (expressed in milliliters per minute) was calculated by subtracting the initial weight from the final weight of the cup (19).

\section{Clinical Procedures}

All subjects received new conventional maxillary and mandibular CDs, which were adjusted in bilateral balanced occlusion by a single dental technician. The mandibular CDs were reinforced with a cobalt-chromium framework to prevent fracture in the anterior region (20). After 2 months of conventional maxillary and mandibular $C D$ use, the study variables were evaluated.

Subsequently, one implant (Titamax; Neodent, Curitiba, PR, Brazil) was installed in the mandibular symphysis region in each patient according to a computerized tomographic plan. Proper positioning of the implant was established with the assistance of a surgical guide. After surgery, the mandibular CD was adjusted and relined with a resilient soft-lining provisional material (Dencril, Pirassununga, São Paulo, Brazil) for use during the 3-month osseointegration period. An equator abutment (Neodent) was adapted on the implant and the intaglio of the mandibular CD was 
adjusted. In this way, the conventional mandibular CD was converted to an SIO. Occlusal adjustment was performed to maintain bilateral balanced occlusion.

\section{Oral Sensorimotor Ability}

OSA was evaluated as described by Hirano et al. (14). Test pieces measuring $8 \times 8 \times 2 \mathrm{~mm}^{3}$ made of raw carrots were prepared in six shapes: circle, ellipse, semicircle, square, rectangle, and triangle. These test pieces were grouped into three pairs of similar geometric forms: circles and ellipses, squares and rectangles, and triangles and semicircles (14).

The evaluation was performed in a quiet environment, with subjects seated in the upright position. Participants were instructed to close their eyes while randomly selected test pieces were placed individually on the tongue. Subjects were allowed to move the test pieces inside the mouth without restraint, and were asked to identify their forms by pointing to the equivalent picture on a chart.

Responses were registered using a three-point scale. Correct responses were given scores of 2 and incorrect responses were given scores of 0 . Responses falling within the same shape group were considered to be partly correct and given scores of 1 (14). Final scores ranged from 0 (all responses were incorrect) to 12 (all responses were correct). The time elapsed before each response was given was also recorded.

\section{Chewing Movements}

Mandibular chewing movements were evaluated using a jaw-tracking kinesiograph device (JT-3D; BioResearch, Milwaukee, Wisconsin, USA). Each subject was seated with the Frankfort plane parallel to the ground and a small magnet was attached temporarily to the artificial incisors of the mandibular prosthesis (21). The device's magnetic sensor was placed on the participant's head and adjusted according to the manufacturer's instructions.

Movements were evaluated during 40 cycles of mastication of an Optocal portion $(22,23)$, counted by the researcher. Tracked jaw movements were displayed on a computer screen as three-dimensional spatial coordinates on the frontal, horizontal, and sagittal axes with the BioPack computer program (BioResearch; SAS Institute Inc., Cary, NC, USA). This program was used to analyze the following parameters: opening, closing, and occlusal phase times; total masticatory cycle time; maximum opening and closing velocities; and opening and closing angles (in the frontal plane).

\section{Masticatory Performance}

The sieving method was used to measure MP. After the 40 cycles of Optocal mastication performed for the chewing movement evaluation, each subject was instructed to expectorate the comminuted particles onto a paper filter. After drying, the particles were submitted to $2 \mathrm{~Hz}$ vibration for $20 \mathrm{~min}$ in a sieving machine (Bertel Industria Metalurgica, Caieiras, SP, Brazil) with a stack of 10 sieves ranging in size from $5.6-\mathrm{mm}$ to $0.5-\mathrm{mm}$ mesh and a bottom plate (22). Particles on each sieve, including the bottom plate, were weighed on an analytical balance. MP was determined according to the median particle size $\left(X_{50}\right)$, calculated using the Rosin-Rammler cumulative function (nonlinear regression analysis), where $X_{50}$ is considered to be the aperture of a theoretical sieve through which $50 \%$ of the chewed particles could pass (22). Thus, lower $X_{50}$ values were taken to represent better MP.

\section{Nutritional Intake}

Subjects were asked to keep a detailed, comprehensive 3-day food diary (2). They were trained to record all food and drink consumption during 3 consecutive days. After diary conclusion, subjects were questioned for additional food clarification (2). Computerized dietary tables were used to evaluate intake of energy (in kilocalories), fat (in grams/ day), carbohydrates (in grams/day), protein (in grams/day), calcium (in milligrams/day), fiber (in grams/day), sodium (in milligrams/day), and iron (in milligrams/day) (24). Each subject's body mass index (BMI, in kilograms/meter ${ }^{2}$ ) was also recorded (12).

\section{Statistical Analysis}

Shapiro-Wilk analysis was performed and confirmed the parametric distribution of some OSA response scores (for triangles, circles, and ellipses), response times (for rectangles, squares, semicircles, and ellipses), masticatory movements, MP, and some markers of nutritional intake (protein, fiber, cholesterol, and calcium). All of these variables were analyzed using the paired $t$ test. Nonparametric distribution was found for other OSA response scores (for rectangles, squares, and semicircles), response times (for triangles and circles) and nutritional intake markers (energy, carbohydrates, fat, sodium, and iron). These non-parametric parameters were analyzed using the Wilcoxon signed rank test. Analyses were performed using SAS software (release 9.1, 2003; SAS Institute Inc., Cary, NC, USA) with a $5 \%$ statistical significance level.

\section{Results}

The study sample consisted of four men and eight women (mean age, $68.6 \pm 5.2$ years). The mean ( \pm standard deviation) salivary flow rate was $1.39 \pm 0.35 \mathrm{ml} / \mathrm{min}$, which is considered to be within the normal range. OSA test responses and response times did not differ according to the conventional CD (OSA scores $=8.92 \pm 3.03$; time of response $=8.52 \pm 1.61)$ vs. SIO (OSA scores $=9.08 \pm 2.57$; 
time of response $=9.36 \pm 3.49$ ).

SIO use was associated with improved maximum opening and closing velocities during chewing $(p<0.05)$ and decreased $X_{50}$ values $(p<0.0001)$, indicating improved MP (Table 1).

The dietary intake data showed a significant decrease in the daily ingestion of sodium with SIO use $(p<0.05)$ (Fig. 1). BMI did not differ significantly between periods of conventional mandibular CD $\left(27.71 \pm 4.75 \mathrm{~kg} / \mathrm{m}^{2}\right)$ and SIO $\left(27.94 \pm 5.32 \mathrm{~kg} / \mathrm{m}^{2}\right)$ use.

\section{Discussion}

This study aimed to elucidate the ability of SIO insertion to influence oral perceptions, masticatory function and nutritional intake of older people with loss of residual ridges height. The results showed that SIO use did not influence OSA in such subjects. In contrast elders using SIO experienced better mastication and reduction of sodium intake compared to $C D$ use.

Oral stereognosis involves the interaction of test pieces with the lips, tongue, and teeth (15). Thus, we expected that greater mandibular prosthesis stability would contribute to better coordination of tongue and lip movements, and thus to improved oral perception. However, this assumption was not confirmed, as the OSA scores and response times of edentulous elders did not differ between periods of conventional CD and SIO use. Yan et al. (5) suggests that

Table 1 . Masticatory movements and masticatory performance with conventional CD and SIO use

\begin{tabular}{lcc}
\hline & CD & SIO \\
\hline Masticatory movements & & \\
Opening time (ms) & $221.26 \pm 47.97$ & $198.25 \pm 42.02$ \\
Closing time (ms) & $320.35 \pm 101.77$ & $323.25 \pm 93.04$ \\
Occlusal phase time (ms) & $230.08 \pm 83.54$ & $205.21 \pm 104.93$ \\
Masticatory cycle time (ms) & $788.96 \pm 156.24$ & $726.70 \pm 94.98$ \\
$\begin{array}{l}\text { Maximum opening } \\
\text { velocity (mm/s) }\end{array}$ & $81.93 \pm 40.75 \mathrm{a}$ & $104.55 \pm 38.35 \mathrm{~b}$ \\
$\begin{array}{l}\text { Maximum closing } \\
\text { velocity (mm/s) }\end{array}$ & $63.46 \pm 27.73 \mathrm{a}$ & $78.97 \pm 39.39 \mathrm{~b}$ \\
$\begin{array}{l}\text { Opening angle } \\
\text { (frontal plane) }\end{array}$ & $101.93 \pm 22.61$ & $100.06 \pm 27.88$ \\
$\begin{array}{l}\text { Closing angle } \\
\text { (frontal plane) }\end{array}$ & $157.29 \pm 100.07$ & $137.65 \pm 77.17$ \\
Masticatory performance & & \\
$\mathrm{X}_{50}$ & $6.27 \pm 0.84 \mathrm{a}$ & $4.57 \pm 0.79 \mathrm{~b}$ \\
\hline
\end{tabular}

Data are reported as mean \pm standard deviation and were analyzed with Student's paired $t$ test. Distinct letters indicate differences between treatments $(p<0.05)$. CD $=$ Complete denture; SIO = Singleimplant overdenture. fitting implant-supported dentures evoke a change in somatosensory and motor inputs to the brain that is markedly different from what occurs with CDs, and only fixed implant prostheses promotes sensory and motor feedback closer to that of the natural dentition due to its wider quantity of implants installed. This brings the idea that SIO may not present enough osseoperception for improvement of OSA. In addition, sensory innervation is found mainly in the dorsal region of the tongue (15) and the main intraoral site for the detection of food particles is on the oral mucous membrane (4). Thus, the SIO may have had little effect on test piece recognition because the lateral edge of the tongue has most contact with the mandibular denture, whereas the dorsal region of the tongue has most contact with the maxillary prosthesis, and this latter was not changed during the study.

Implant therapy can restore the motor feedback pathway to the central nervous system in edentulous patients (5) reducing masticatory cycle duration (24), which positively impacts masticatory function. Therefore, while analyzing chewing movements of our edentulous patients rehabilitated with SIO, we expected that the SIO would also improve others chewing parameters. However, only the opening and closing velocities were enhanced by SIO use. As the lack of periodontal mechanoreceptors in edentulous patients compromises the spatial control of mandibular movements (3) the insertion of a single implant into an atrophic mandible may not be sufficient to induce significant differences in more chewing movement parameters. The greater retention provided by the SIO is probably responsible for our increased opening and closing velocities. This finding is in accordance with a recent kinesiograph study that showed improved on vertical opening of elderly participants rehabilitated with SIO prostheses after 3 months of use (25).

As expected, the MP of edentulous elderly patients was greater after SIO insertion than with conventional CD use. In spite of using different material test, previous studies $(9,26)$ also showed an improvement on MP and masticatory efficiency. This finding can be explained by implants placement, which can increase masticatory muscle activity of patients with edentulous mandible (13), and improve mastication as a consequence (5). In addition, the better retention and stability provided by a SIO (8), promoting resistance of the prosthesis against horizontal movements (27), could also contributes to explain the reduction of $X_{50}$ values of such patients.

MP is related to the ability to ingest food, and directly influences digestion and nutrient absorption (2). Thus, chewing efficiency may allow individuals to select healthier food, thereby improving their nutrient intake. However, despite improved MP, our results showed no change in 
nutrient intake after 2 months of SIO use. The exception was sodium intake, which decreased after SIO placement. This result contradicts those of a previous study (28), which showed that improved retention afforded by the placement of implants and ball-attachment retainers over free-end removable partial dentures improved the intake of several nutrients. However, different from the subjects of the previous study (28), we studied completely edentulous elders with loss of residual mandibular ridges height, which may partially explain this difference. In addition, longer SIO use may be required for observable improvement in nutritional results among elders with critical bone height situations. Thus, further studies with long-term evaluation are needed.

Raw and non-industrialized foods are considered to have lower sodium contents (29) than industrialized and processed foods. Thus, despite the lack of difference in the majority of nutrient intakes between prosthetic treatments, the significant decrease in sodium ingestion with SIO use suggests that the quality of the diet improved in our elderly subjects due to the consumption of low-sodium foods. As sodium ingestion is related to some cardiovascular diseases affecting elders (29), SIO use may have improved the systemic health condition in our elderly population through

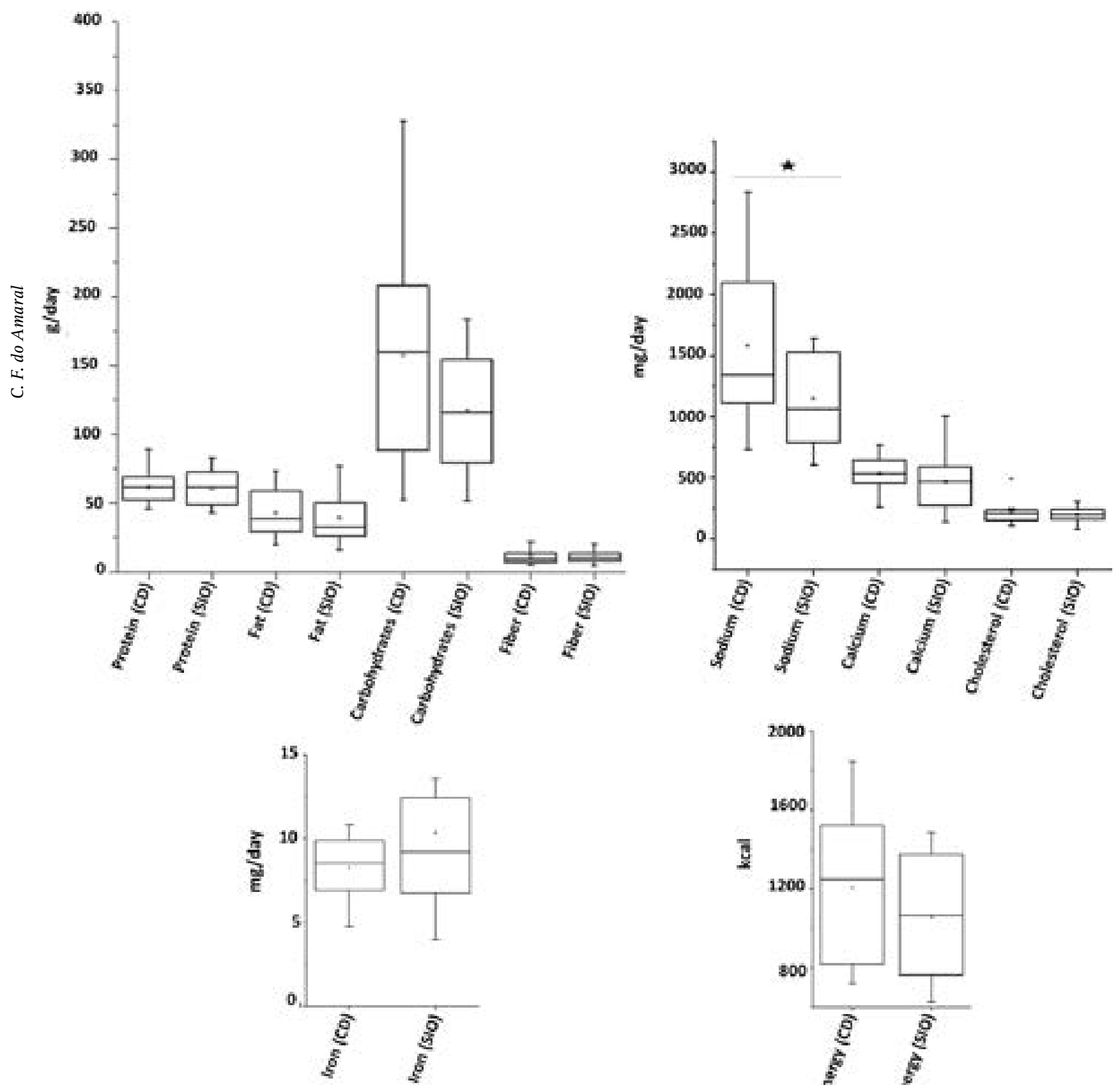

Figure 1. Nutritional intake of elderly subjects with conventional CD and SIO use ( $\mathrm{n}=12)$. 
improvement of oral function. Nevertheless, nutritional intervention such as dietary advice could increase the diet quality intake of edentulous elderly patients rehabilitated by implant-supported mandibular overdentures (30). Further studies are encouraged to propose a protocol of such partnership between dental interventions and geriatricians concerned with elders' nutrition.

It is important to mention that during sample selection, the presence of signs and symptoms of temporomandibular disorders was evaluated by asking the elderly about the presence of pain in the orofacial region, and by palpation of masticatory muscles (31). Thus, since a validated instrument such as the RDC/TMD (Research Diagnostic Criteria for Temporomandibular Disorders) was not used, these exclusion criteria should be cautiously interpreted. In addition, this study evaluated subjects just after two months of using each prosthetic treatment, which can limit findings. Irrespective of that, our study provides information and may guide clinicians on decision making about prosthetic treatment directed to the elderly people. Considering that some elders would not be subjected to invasive surgical procedures to implants insertion, and most of them have financial limitations, our results show that SIO can improve mastication. Therefore, SIO can be considered a simplified technique overdenture and may be an alternative for elders whom have difficult to adapt with conventional $C D$ due to the loss of residual alveolar bone height.

Despite the short-term evaluation, this study showed that opening and closing velocities of the mandible during chewing and MP of elderly people are improved by using SIO when compared to conventional CD use. However, OSA and intake of the most nutrients remains the same after both prosthetic therapies, with the exception of sodium ingestion, which was decreased after SIO use.

\section{Resumo}

A utilização de overdentures suportadas por dois implantes melhora a mastigação de pacientes idosos edêntulos que apresentam rebordos residuais reabsorvidos. No entanto, pouco se sabe sobre os efeitos de overdentures suportadas por único implante central mandibular (SIO) em relação à percepção oral e função mastigatória em tais idosos. 0 atual estudo comparou os efeitos de próteses totais convencionais (CD) e SIO na capacidade de sensorimotora oral (OSA), função mastigatória e ingestão nutricional de idosos com altura de rebordos mandibulares tipo III e IV de acordo com a Colégio Americano de Prótese. Doze idosos receberam primeiramente novas $C D$ convencionais, as quais, posteriormente, foram transformadas em SIO. Variáveis foram avaliadas após o uso de cada prótese durante 2 meses. Para avaliar OSA, os idosos fecharam os olhos e testaram oralmente a identificação de formatos geométricos confeccionados de cenouras cruas. Um dispositivo cinesiográfico foi utilizado para medir os movimentos durante a mastigação de material de teste (Optocal). A performance mastigatória (MP) foi determinada com o método de fracionamento de peneiras e um diário de alimentação aplicado por 3 dias consecutivos verificou a ingestão de nutrientes com base em uma Tabela Brasileira Padrão de Composição de Alimentos. Os dados foram analisados utilizando os testes Wilcoxon signed rank test e Student's paired $t$ test $(p<0,05)$. OSA resultados não diferiram de acordo com 0 tipo de prótese. No entanto, as velocidades de abertura e fechamento durante a mastigação e MP aumentaram após a inserção de $\operatorname{SIO}(p<0,05)$. Embora não tenha sido observada diferença na ingestão da maioria dos nutrientes, a ingestão de sódio diminuiu após a inserção de $\operatorname{SIO}(p<0,05)$. 0 uso de SIO não teve efeito sobre OSA, mas melhorou significativamente a mastigação e a ingestão de sódio de idosos com altura de rebordos residuais reduzidas (Registro Brasileiro de Ensaios Clínicos \# RBR-3kgttj).

\section{Acknowledgements}

This study was supported by the São Paulo Research Foundation (Grant \#2015/21704-1).

\section{References}

1. Ikebe $K$, Amemiya $M$, Morii $K$, Matsuda $K$, Furuya-Yoshinaka $M$, Yoshinaka $M$, et al. Association between oral stereognostic ability and masticatory performance in aged complete denture wearers. Int J Prosthodont 2007;20:245-250.

2. Moynihan $P$, Thomason M, Walls A, Gray-Donald K, Morais JA, Ghanem $\mathrm{H}$ et al. Researching the impact of oral health on diet and nutritional status: methodological issues. J Dent 2009;37:237-249.

3. Trulsson M. Force encoding by human periodontal mechanoreceptors during mastication. Arch Oral Biol 2007;52:357-360.

4. Crum RJ, Loiselle RJ. Oral perception and proprioception: a review of the literature and its significance to prosthodontics. J Prosthet Dent 1972;28:215-230.

5. Yan C, Ye L, Zhen J, Ke L, Gang L. Neuroplasticity of edentulous patients with implant-supported full dentures. Eur J Oral Sci 2008;116:387-393.

6. van Kampen FM, van der Bilt A, Cune MS, Fontijn-Tekamp FA, Bosman F. Masticatory function with implant-supported overdentures. J Dent Res 2004;83:708-711.

7. Srinivasan M, Makarov NA, Herrmann FR, Müller F. Implant survival in 1 - versus 2-implant mandibular overdentures: a systematic review and meta-analysis. Clin Oral Implants Res 2016;27:63-72.

8. Harder S, Wolfart S, Egert C, Kern M. Three-year clinical outcome of single implant-retained mandibular overdentures-results of preliminary prospective study. J Dent 2011;39:656-661.

9. Grover $M$, Vaidyanathan AK, Veeravalli PT. OHRQoL, masticatory performance and crestal bone loss with single-implant, magnetretained mandibular overdentures with conventional and shortened dental arch. Clin Oral Implants Res 2014;25:580-586.

10. Joshipura K, Willett W, Douglass C. The impact of edentulousness on food and nutrient intake. J Amer Dent Assoc 1996;127:459-467.

11. Lee JS, Weyant RJ, Corby P, Kritchevsky SB, Harris TB, Rooks R, et al. Edentulism and nutritional status in a biracial sample of wellfunctioning, community-dwelling elderly: the health, aging, and body composition study. Amer J Clin Nutrition 2004;79:295-302.

12. Morais JA, Heydecke G, Pawliuk J, Lund JP, Feine JS. The effects of mandibular two-implant overdentures on nutrition in elderly edentulous individuals. J Dent Res 2003;82:53-58.

13. Chen L, Xie 0 , Feng $H$, Lin Y, Li J. The masticatory efficiency of mandibular implant-supported overdentures as compared with toothsupported overdentures and complete dentures. J Oral Implantol 2002;28:238-243.

14. Hirano K, Hirano S, Hayakawa I. The role of oral sensorimotor function in masticatory ability. J Oral Rehabil 2004;31:199-205.

15. Jacobs R, Bou Serhal C, van Steenberghe D. Oral stereognosis: a review of the literature. Clin Oral Investig 1998;2:3-10.

16. Amaral CF, Pinheiro MA, Rodrigues Garcia RCM. Psychometric analysis and masticatory efficiency of elderly people with single-implant overdentures. Int J Oral Maxillofac Implants 2018;33:1383-1389.

17. McGarry TJ, Nimmo A, Skiba JF, Ahlstrom RH, Smith CR, Koumjian JH. Classification system for complete edentulism. J Prosthodont 1999;8:27-39.

18. Rise J. Validation of data on demand and need for dental treatment in 
an elderly population. Community Dent Oral Epidemiol 1979;7:1-5.

19. van der Bilt A. Assessment of mastication with implications for oral rehabilitation: a review. J Oral Rehabil 2011;38:754-780.

20. Gonda $T$, Ikebe K, Dong J, Nokubi T. Effect of reinforcement on overdenture strain. J Dent Res 2007;86:667-671.

21. Gonçalves TM, Vilanova LS, Gonçalves LM, Rodrigues Garcia RC. Effect of complete and partial removable dentures on chewing movements. J Oral Rehabil 2014;41:177-83.

22. Slagter AP, Bosman F, Van der Bilt A. Comminution of two artificial test foods by dentate and edentulous subjects. J Oral Rehabil 1993;20:159176.

23. Pocztaruk Rde L, Frasca LC, Rivaldo EG, Fernandes Ede L, Gavião MB. Protocol for production of a chewable material for masticatory function tests (Optocal - Brazilian version). Braz Oral Res 2008;22:305310.

24. Karlsson S, Jemt T. Adaptive changes of masticatory movement characteristics after rehabilitation with osseointegrated fixed prostheses in the edentulous jaw: a 10-year follow-up study. Int J Oral Maxillofac Implants 1991;6:259-263.

25. Policastro VB, Paleari AG, Leite ARP, Mendoza-Marin DO, Cassiano AFB, Shaddox LM, Compagnoni MA, Pero AC. A Randomized clinical trial of oral health-related quality of life, peri-Implant and kinesiograph parameters in wearers of one-or two-implant mandibular Overdentures. J Prosthodont 2018. [Epub Ahead of Print. doi: 10.1111/ jopr.12796].
26. Bhat $\mathrm{S}$, Chowdhary R, Mahoorkar S. Comparison of masticatory efficiency, patient satisfaction for single, two, and three implants supported overdenture in the same patient: a pilot study. J Indian Prosthodont Soc 2016;16:182-186.

27. Chen IC, Brudvik JS, Mancl LA, Rubenstein JE, Chitswe K, Raigrodski AJ. Freedom of rotation of selected overdenture attachments: an in vitro study. J Prosthet Dent 2011;106:78-86.

28. Campos $\mathrm{CH}$, Gonçalves TM, Rodrigues Garcia RC. Implant retainers for free-end removable partial dentures affect mastication and nutrient intake. Clin Oral Implants Res 2014;25:957-961.

29. World Health Organization. 2006. Oral health in ageing societies: integration of oral health and general health. 1-3 June 2005. (WHOGeneva).

30. Moynihan PJ, Elfeky A, Ellis JS, Seal CJ, Hyland RM, Thomason JM. Do implant-supported dentures facilitate efficacy of eating more healthily? J Dent 2012;40:843-50.

31. Luo $Y$, McMillan AS, Wong MC, Zheng J, Lam CL. Orofacial pain conditions and impact on quality of life in community-dwelling elderly people in Hong Kong. J Orofac Pain 2007;21:63-71.

Received May 10, 2018 Accepted August 28, 2018 